\title{
Multiple Trichilemmal Cysts of the Scalp
}

\author{
REINHARD E. FRIEDRICH ${ }^{1}$ and WALDEMAR WILCZAK ${ }^{2}$ \\ ${ }^{1}$ Department of Oral and Craniomaxillofacial Surgery, \\ Eppendorf University Hospital, University of Hamburg, Hamburg, Germany; \\ ${ }^{2}$ Institute of Pathology, Eppendorf University Hospital, University of Hamburg, Hamburg, Germany
}

\begin{abstract}
Different entities can be the cause of scalp neoplasia. In a phenotype with multiple cystic scalp lesions, the diagnosis must be made with particular caution because the appearance of apparently benign tumors does not necessarily correspond to the biological behaviour of the lesions. This case report describes diagnosis and therapy of a patient with multiple cystic tumors confined to the scalp. Diagnosis of benign lesions all over the scalp allowed an aesthetically pleasing surgical treatment result. Long-term follow-up control was offered to the patient because the histological diagnosis identified further small tumors of the same type as the large lesions, so further neoplasms are likely to develop.
\end{abstract}

In the scalp, very different neoplasms can arise, which differ greatly in biological behavior. In rare cases, cysts or cyst-like lesions may develop in the scalp, as large exophytic tumors and are visually perceived to be neoplasias. The distinction of cystic scalp lesions has been controversial until recently. Histogenetic aspects are highlighted in the diagnosis of cysts and cyst-like lesions of the scalp (1-3). Cystic lesions of the scalp require careful examination because malignant tumors can develop from these lesions (4-6). This report describes a rare case of multiple nodular and partially cyst-like lesions of the scalp, initially thought to be schwannomas.

\section{Case Report}

The 44-year-old female patient came to the Outpatients Clinic of the Department of Oral and Craniomaxillofacial Surgery, Eppendorf University Hospital, to remove tumors

Correspondence to: Reinhard E. Friedrich, MD, DMD, Ph.D., FEBOMFS, Department of Oral and Craniomaxillofacial Surgery, Eppendorf University Hospital, University of Hamburg, Martinist. 52, D-20246 Hamburg, Germany. Tel: +49 40741053259, e-mail: rfriedrich@uke.de

Key Words: Trichilemmal cyst, scalp, scalp tumors, plastic surgery. on her scalp for aesthetic reasons. The patient had been referred for surgical treatment for suspected schwannomas of the skull. She reported that tumors in her scalp had occurred many years ago and had grown slowly since then (Figure 1A-C). During this time, other tumors have appeared in other scalp regions. However, other body regions than the scalp were not affected by these tumors. Relatives are not affected by this disease. She had been able to cover the tumors for a long time by her hair and thus avoided a surgical treatment. It was only after the surgical intervention that the patient, by consulting her mother, was able to provide information that two small scars in the parietal area had come from previous operations during childhood in which her cyst-like tumors had been removed. At no time was an ulceration of the tumors noted by the patient. At the time of the examination, large egg-shaped tumors were clearly visible. However, other tumors could be seen or palpated below the entire scalp. All the multiple tumors were formed under intact skin. The hair was thinned above the tumors (Figure 1A-C). Small tumors were firm on palpation whereas the surfaces of large tumors were easily depressible in some places and the whole tumor was movable. The clinical findings did not allow a clear diagnosis. However, the local findings were not an argument in favor of the diagnosis of multiple schwannomas, both from the palpation, the number and location of the tumors and the restriction of tumor growth on the scalp. In order to detect the potential extent of the tumors on the bone, a cranial computed tomography was performed. Here, some large, partially liquid-filled subcutaneous masses but also numerous small, solid lesions resting on the skullcap with a broad base, apparently without infiltrating the bone, were found. The patient's history and findings were considered as evidence of multiple benign lesions.

According to the CT findings and the clinical examination, development of multiple scalp cysts in different developmental or growth stages was assumed, which covered the entire hairy area. Bone below lesions was intact (Figure 2 ). The claim to a total removal of the tumors would have required the removal of the scalp or at least would have 


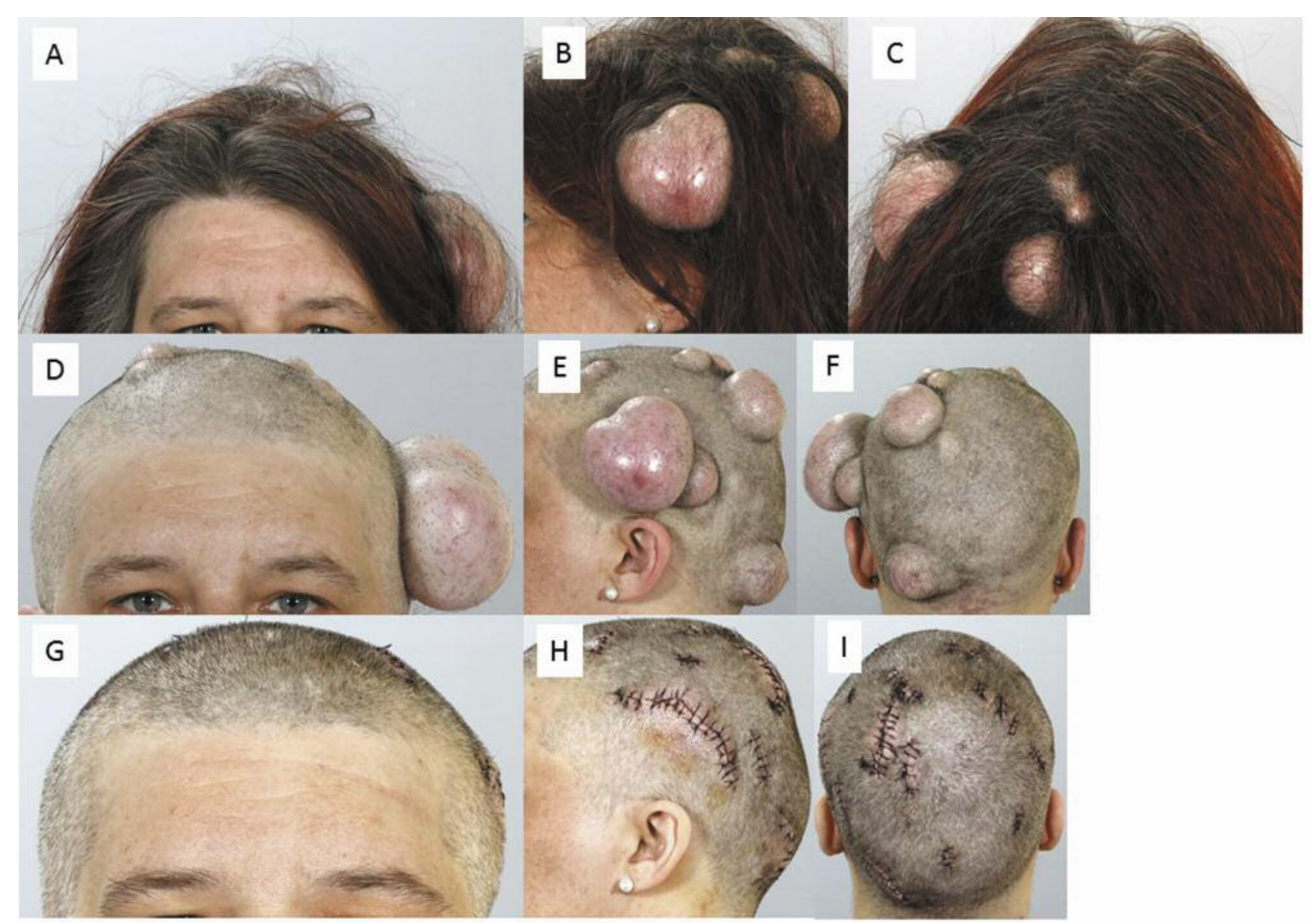

Figure 1. Clinical aspect of the patient with multiple trichilemmal cysts of scalp prior to surgery $(A-F)$, with covering hair $(A-C)$ and after shaving $(D-F)$ : frontal $(A, D)$, lateral $(B, E)$ and posterior $(C, F)$ aspect of tumors. The tumors are of different size, situated below intact skin and are asymmetrically distributed in the scalp. G-I: Aspect of the scalp in same projections as presented in A-F following ablative surgery and wound closure.

resulted in a substantial loss of the patient's hair. This measure had been rejected by the patient and was also not planned from a surgical point of view because it was probably a benign condition that could be controlled by local excision.

Therefore, a removal of the tumors was scheduled, in which the hair of the patient was preserved. For surgery, the patient appeared with shaved hair (Figure 1D-F). This situation clearly indicated the true extent of multiple tumors. In general anesthesia skin was gently incised over the apex of the respective large tumors, and the cyst-like tumor surrounded by a pseudo-capsule was extirpated (Figure 3). In some cysts, the capsule walls were very thin and cracked during the preparation so that the bright mucilaginous keratinous cyst contents became visible (Figure 3B and C). After the removal of the cysts, the surplus of the skin was excised, always allowing the tension-free wound closure (Figure 1G-I). By palpation, numerous small tumors could be identified and excised during further examination of the scalp (Figure 3D and E). Healing was uneventful and patient was satisfied by the surgical treatment.

Histology. The cysts were lined by squamous epithelium, showing trichilemmal keratinization without formation of kerato-hyaline granules. The cysts were resembling a pattern that is seen in the external root sheath in the region of the hair follicle isthmus. The cysts were multifocally accompanied by inflammatory and regressive changes. There were no signs of enhanced proliferation and there was no cellular atypia in the cysts. Final diagnosis was multiple trichilemmal cysts of the scalp (Figure 4).

\section{Discussion}

The trichilemmal cyst (TC) is a benign lesion of the skin. Usually, patients with TC are middle-aged individuals, predominantly women, who have known the lesions for a long time, occasionally since childhood $(6,7)$. The multiple 

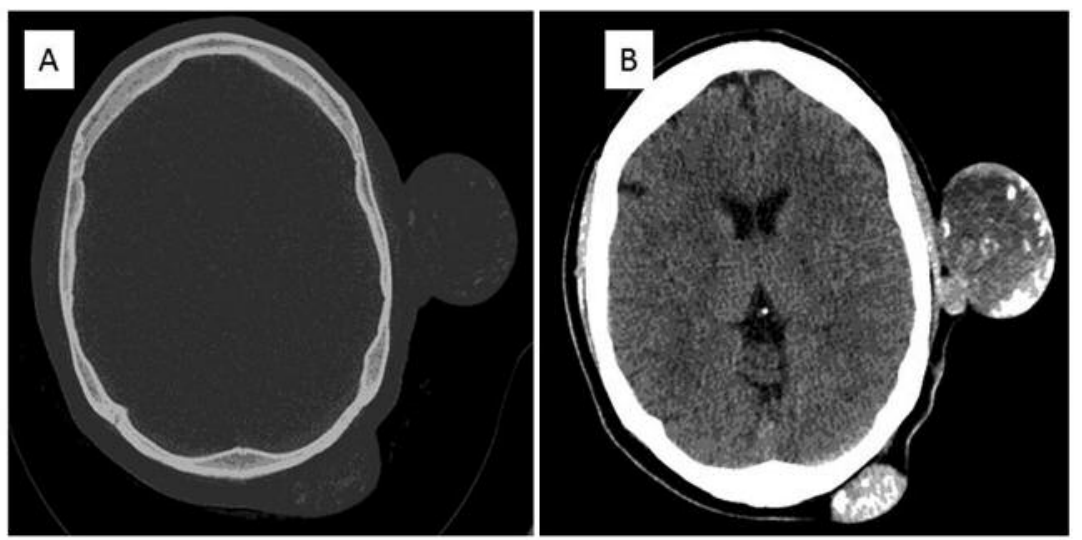

Figure 2. Computed tomography of the patient's calvaria, axial sections. (A) The lesions appear continuous to the scalp and the bone is intact. (B) The internal composition of large lesions appears inhomogeneous. The cysts appear filled with fluid combined with marginally arranged, small, rounded hyperdense compartments.

appearance of the cyst in the hairy region of the head is typical but not obligatory $(8,9)$. In individual cases, TCs of the scalp can extend well beyond this region $(6,10)$ as well as arising in completely different skin regions of the body (3).

TCs can arise in direct topographic relation to other lesions of the skin $(11,12)$, have been described in association with syndromes (1), may be triggered by local trauma (13), and there are reports of familial accumulation of isolated lesions (14). TCs occurring in the scalp area are predominantly an aesthetic burden of patients (15). Of considerable diagnostic and clinical importance is the fact that (multiple) TCs can occur in combination with a neoplasm or is a pre-stage of a neoplasm $(2,4)$. TC shows no higher proliferative activity. If a higher proliferative activity is detected in the tissue, the entity is called proliferating TC (2). Transition of proliferative TC to trichilemmal tumor is not well defined (16). The most pronounced dedifferentiation of TC is the squamous cell carcinoma (SCC) that has developed from a TC $(1,3,4,17$ 19). SCC can develop both from TCs and from proliferating $\mathrm{TC} /$ trichilemmal tumors $(5,6,17,20)$. The pathogenesis of this rare neoplasm is unknown. From individual reports and collection casuistry it can be concluded that there may be a continuum from a long-standing cyst to the benign tumor or even carcinoma (6). While local excision is a sufficient treatment for $\mathrm{TC}$, resection, including covering skin and safety margin, should be performed for neoplastic lesions (16). For proven carcinomas, removal of the regional lymph nodes should be considered $(4,17,20)$. However, despite adequate neck dissection, regional metastases can occur (21).

The clinical distinction between benign trichilemmal tumor and SCC can be difficult or impossible. For example, ulcerations of the lesions occur not only in SCC arising from TC $(2,7,21)$, but also in proliferating trichilemmal tumor
(9). Preliminary diagnosis of TC was found in one case to be a metastasis of hepatocellular carcinoma (22). Another case was initially assessed as TC but proved to be a solitary schwannoma (23). When TC is present in large numbers, further skin lesions can also be observed occasionally in the resected skin specimen (24). Therefore, careful histological examination of the entire sample is advisable

The radiological characteristics of the TC arising in the scalp have been described for both computed tomography (CT) and magnetic resonance imaging (MRI) (25-27). In MRI, the heterogeneous components of the cyst are clearly visible (27). In CT, multiple TCs can be visualized as rimenhancing ovoid complex cystic masses (26). The lesions are sharply defined masses that do not infiltrate the subcutaneous tissue. In individual lesions, intra-cystic mineralization may occur. The calvaria under the TC is intact, erosions of the bone do not belong to the typical picture of this entity (26). The radiological picture suggests a benign lesion, but the differential diagnosis cannot be established by imaging. In one case, a turban tumor with malignancy was initially suspected based on imaging and evidence for SCC in a biopsy of the lesion (26). A so-called turban tumor can cause a phenotype similar to multiple TCs with egg-shaped cutaneous tumours of the scalp. The turban tumor, like multiple TCs, also preferentially occurs in middle-aged women. The differential diagnosis is histological, whereby the turban tumor is composed of dermal cylindromas (28, 29). Malignant neoplasm arising from TC of the scalp can destroy the bone and spread intracranially (5). Single reports describe calvaria erosions in connection with extensive turban tumor (30). Therefore, although this radiological finding is characteristic of tumor biology in the individual case, it is not a reliable parameter for the diagnosis of a malignant tumor. 

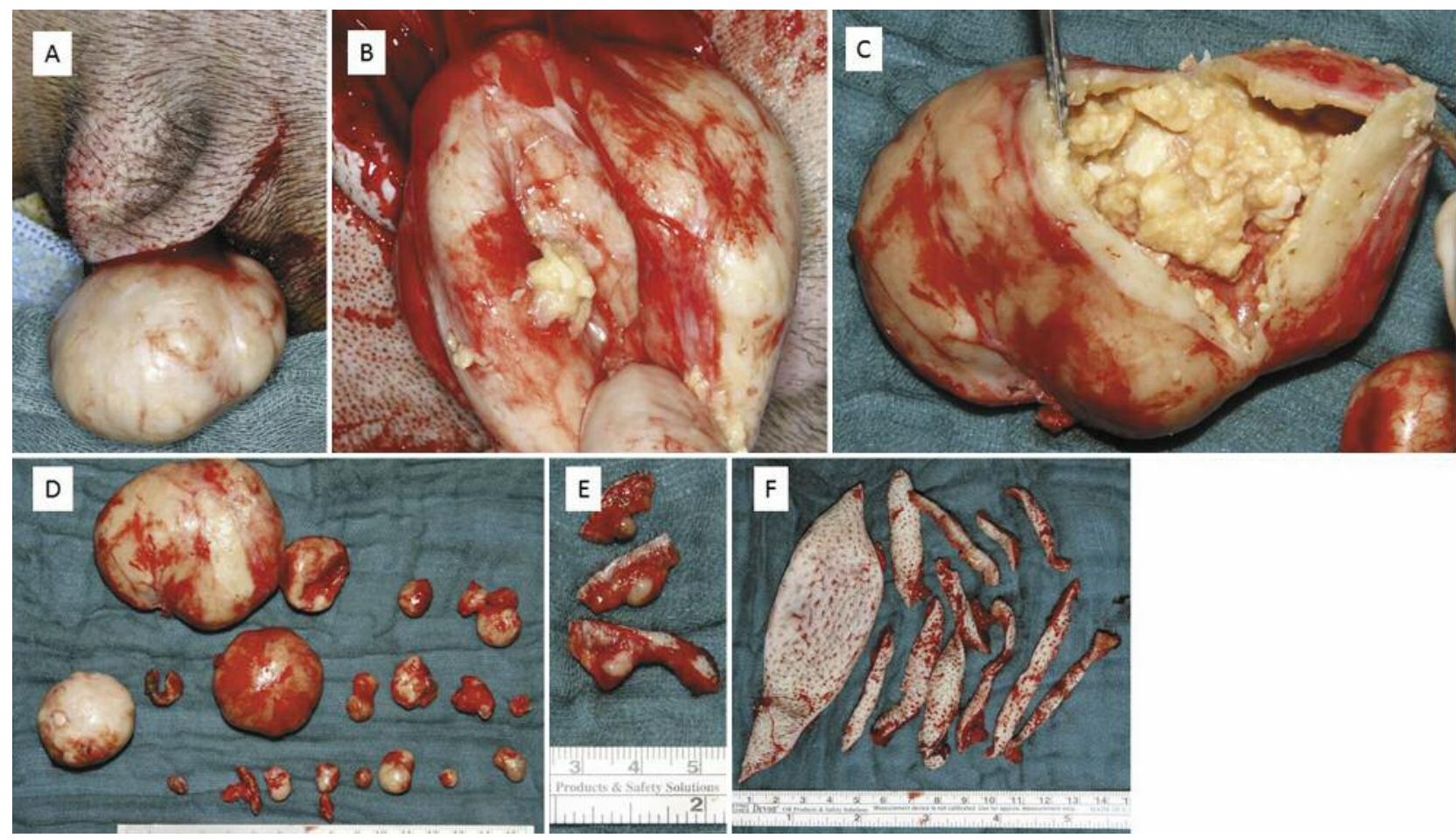

Figure 3. Representative photographs of the surgical procedure. (A) The lesions are easily detachable from covering skin, but the lesion's shell tears easily on pulling at the roundish tumor $(B) .(C)$ The cyst content is partly friable to mushy, partly liquid. (D) The cysts vary in size and indicate that these lesions apparently developed over a very long period of time and at different time points. $(F)$ Excision of the cysts creates a significant excess of skin which has been dissected.
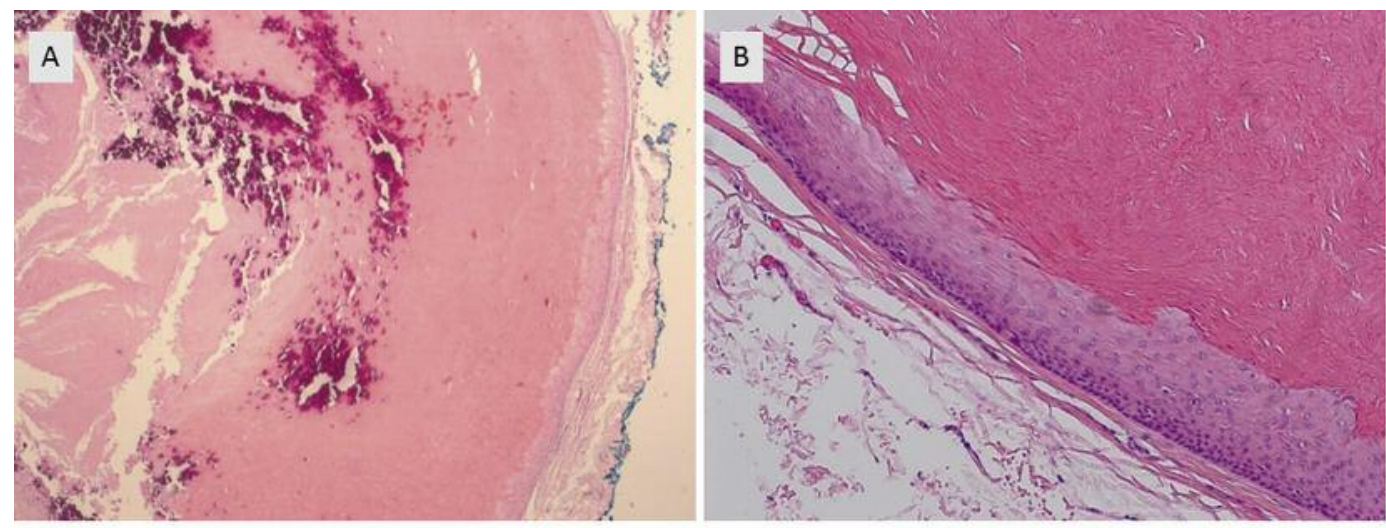

Figure 4. Trichilemmal cyst in overview (A) and detail (B). (A) Cystic lesion lined by stratified squamous epithelium that lacks a granular cell layer. The cyst is filled with compact keratin. In Figure B the desquamation of keratin in the cyst lumen can be seen. The cystic lesion shows no nuclear atypia nor dyskeratotic cells. Number of mitoses is very low.

Treatment is surgical and consists of local excision of the cysts. Excision of the cyst without resection of the covering skin is adequate for the treatment of TC (24). However, careful topographical assignment of every specimen is required for histological examination, because the synchronous occurrence of TCs, proliferating TC (tumor) (10) and even SCC is known in (multiple) TC $(4,31)$. In the latter cases, the complete resection of the lesion with skin and safety margin is indispensable, so that in this situation more extensive ablative and reconstructive measures are necessary. 


\section{Conclusion}

The diagnosis and treatment of a patient with multiple TCs is described. Multiple benign lesions were diagnosed in the presented case justifying a conservative surgical approach that allowed aesthetic restoration of the natural head shape and gentle handling of the hairy scalp. However, phenotypically similar tumors can arise from TCs that show an uncertain biological behavior (31) or may even degenerate into malignant neoplasms, requiring radical surgical intervention (32).

\section{Authors' Contributions}

REF treated the patient, researched and examined the literature on the subject, and wrote the manuscript. WW has determined the histological diagnosis. Both Authors have reviewed the manuscript and released it for publication.

\section{Acknowledgements}

The Authors would like to thank the patient for her written consent to publish this report.

\section{References}

1 Cohen PR and Rapini RP: Nevus with cyst. A report of 93 cases Am J Dermatopathol 15: 229-234, 1993. PMID: 8517494.

2 Poiares Baptista A, Garcia E, Silva L and Born MC: Proliferating trichilemmal cyst. J Cutan Pathol 10: 178-187, 1983. PMID: 6863684

3 Sau P, Graham JH and Helwig EB: Proliferating epithelial cysts. Clinicopathological analysis of 96 cases. J Cutan Pathol 22: 394406, 1995. PMID: 8594071.

4 Saida T, Oohara K, Hori Y and Tsuchiya S: Development of a malignant proliferating trichilemmal cyst in a patient with multiple trichilemmal cysts. Dermatologica 166: 203-208, 1983. PMID: 6852333

5 Lobo L, Amonkar AD and Dontamsetty VV: Malignant proliferating trichilemmal tumour of the scalp with intra-cranial extension and lung metastasis-a case report. Indian J Surg 78: 493 495, 2016. PMID: 28100948. DOI: 10.1007/s 12262-015-1427-0

6 Asilian A, Siadat AH, Shahmoradi Z, Shariat S, Moghadam NA and Soozangar $\mathrm{H}$ : Multiple giant pilar cyst distributed over the body since childhood. Indian J Dermatol 61: 121, 2016. PMID: 26955134. DOI: $10.4103 / 0019-5154.174097$

7 Jha AK, Sinha R, Prasad S and Kumar S: Multiple trichilemmal cysts of the scalp in a young male. Int J Trichology 7: 167-169, 2015. PMID: 26903745. DOI: 10.4103/0974-7753.171576

8 Leung LK: Differential diagnosis of soft scalp lumps. BMJ Case Rep pii: bcr0720114492, 2011. PMID: 22674591. DOI: 10.1136/ bcr.07.2011.4492

9 Yuyucu Karabulut Y and Senel E: Two large nodules on the scalp of a 60-year-old woman. Clin Exp Dermatol 40: 97-98, 2015. PMID: 25251988. DOI: 10.1111/ced.12468

10 Hendricks DL, Liang MD, Borochovitz D and Miller T: A case of multiple pilar tumors and pilar cysts involving the scalp and back. Plast Reconstr Surg 87: 763-767, 1991. PMID: 2008475.
11 Stavrianeas NG, Katoulis AC, Stratigeas NP, Karagianni IN, Patertou-Stavrianea $\mathrm{M}$ and Varelzidis AG: Development of multiple tumors in a sebaceous nevus of Jadassohn. Dermatology 195: 155-158, 1997. PMID: 9310725.

12 Flórez A, Peteiro C, Sánchez-Aguilar D, Fernández-Redondo V, Pereiro Ferreirós $M$ and Toribio J: Three cases of type 2 segmental manifestation of multiple glomus tumors: association with linear multiple trichilemmal cysts in a patient. Dermatology 200: 75-77, 2000. PMID: 10681623. DOI: 10.1159/000018324

13 Erdem H, Yildirim U, Uzunlar AK, Sahiner C, Ozcelik D and Toplu G: Posttraumatic giant proliferating trichilemmal cysts on the parietal region of the scalp. Indian J Dermatol Venereol Leprol 77: 707-709, 2011 PMID: 22016280. DOI: 10.4103/ 0378-6323.86488

14 Sadath HN, Ramachandra S, Kumar MA and Haritha K: Multicentric calcified trichilemmal cysts with alopecia universalis affecting siblings. Indian J Dermatol Venereol Leprol 79: 88-91, 2013. PMID: 23254735. DOI: 10.4103/0378-6323.104675

15 Dewanda NK and Midya M: Baker's dozen on the scalp: An interesting case of multiple trichilemmal cyst. J Cutan Aesthet Surg 7: 67-68, 2014. PMID: 24761109. DOI: 10.4103/09742077.129994

16 Bengoechea-Beeby MP, Velasco-Osés A and Casado-Pérez C: Multiple proliferating trichilemmal tumors and cysts involving the scalp: report of a case. J Oral Maxillofac Surg 52: 985-986, 1994. PMID: 8064466.

17 Dubhashi SP, Jadhav SK, Parasnis A and Patil CS: Recurrent malignant proliferating trichilemmal tumor with lymph node metastasis in a young woman. J Postgrad Med 60: 400-402, 2014. PMID: 25370551. DOI: 10.4103/0022-3859.143973

18 Weiss J, Heine $M$, Grimmel $M$ and Jung EG: Malignant proliferating trichilemmal cyst. J Am Acad Dermatol 32(5 Pt 2): 870-873, 1995. PMID: 7722047.

19 Morgado B, Agostini P, Rivero A and Silva N: Extensive and ulcerated malignant proliferating trichilemmal (pilar) tumour, arising from multiple, large, degenerated trichilemmal (pilar) cysts. BMJ Case Rep pii: bcr2015209785, 2016. PMID: 26857582. DOI: $10.1136 /$ bcr-2015-209785.

20 Mori O, Hachisuka $\mathrm{H}$ and Sasai Y: Proliferating trichilemmal cyst with spindle cell carcinoma. Am J Dermatopathol 12: 479484, 1990. PMID: 1700885.

21 Kruse-Lösler B, Kleinheinz J, Werkmeister R, Piffko J, Metze $\mathrm{D}$ and Joos U: Gigantic proliferating trichilemmal cyst of the scalp with central carcinoma and lymph node metastasis. Mund Kiefer Gesichtschir 2: 216-219, 1998. PMID: 9738372.

22 Polat $\mathrm{G}$ and Sade R: Calvarial mass confused with trichilemmal cyst: Hepatocellular cancer metastasis. J Craniofac Surg 28: e124-e125, 2017. PMID: 28005654. DOI: $10.1097 /$ SCS.0000 000000003298

23 Mohan $\mathrm{KH}$ and Manjunath $\mathrm{H}$ : Cutaneous schwannoma masquerading as trichilemmal cyst over scalp in a young male. Indian J Dermatol 58: 407, 2013. PMID: 24082208. DOI: 10.4103/0019-5154.117338

24 Ibrahim AE, Barikian A, Janom H and Kaddoura I: Numerous recurrent trichilemmal cysts of the scalp: differential diagnosis and surgical management. J Craniofac Surg 23: e164-e168, 2012. PMID: 22446459. DOI: 10.1097/SCS.0b013e31824cdbd2

25 Kitajima K, Imanaka K, Hashimoto K, Hayashi M, Kuwata Y and Sugimura K: Magnetic resonance imaging findings of proliferating trichilemmal tumor. Neuroradiology 47: 406-410, 2005. PMID: 15889245. DOI: 10.1007/s00234-004-1328-6 
26 Chang SJ, Sims J, Murtagh FR, McCaffrey JC and Messina JL: Proliferating trichilemmal cysts of the scalp on CT. AJNR Am J Neuroradiol 27: 712-714, 2006. PMID: 16552022.

27 Adachi N, Yamashita T and Ito H: Differential diagnosis of scalp trichilemmal cyst on MRI. Dermatology 193: 263-265, 1996. PMID: 8944356. DOI: 10.1159/000246262

28 Munger BL, Graham JH and Helwig EB: Ultrastructure and histochemical characteristics of dermal eccrine cylindroma (turban tumor). J Invest Dermatol 39: 577-595, 1962. PMID: 13936620.

29 Reynes M, Puissant A, Delanoe J, Noury-Dupperrat G and Saurat JH: Ultrastructural study of cylindroma (Poncet-Spiegler tumor). J Cutan Pathol 3: 95-101, 1976. PMID: 186497.

30 Friedrich RE: Dermal cylindroma of the scalp (turban tumour) and subjacent calvarian defects. Anticancer Res 30: 1793-1797, 2010. PMID: 20592381.
31 Yoleri L, Baŝer NT and Kandiloğlu AR: Malignant proliferating trichilemmal tumor arising in multiple trichilemmal cysts. Ann Plast Surg 43: 575-576, 1999. PMID: 10560883.

32 Shah A, Akram J, Abdelaal A, Alateeq L, Ben-Gashir M and Hammouda A: Cystic poorly differentiated squamous cell carcinoma of the scalp, a rare scalp tumor: Case report and literature review. Int J Surg Case Rep 60: 21-24, 2019. PMID: 31185453. DOI: $10.1016 /$ j.jjscr.2019.05.055

Received June 30, 2019

Revised July 3, 2019

Accepted July 4, 2019 